\title{
A Feasibility of a Passive Ventilation System with a Thermal Damper - Simulations and measurement results of an experimental house in a mild region of Japan -
}

\author{
Motoya Hayashi ${ }^{1, *}$, Hoon kim $^{1}$, Yoshinori Honma ${ }^{2}$ and Junichiro Matsunaga ${ }^{3}$ \\ ${ }^{1}$ National Institute of Public Health, 2-3-6 Minami Wako City Saitama Prefecture, Japan \\ ${ }^{2}$ Miyagigakuin Women's University, 9-1-1 Sakuragaoka Aobaku Sendai City Miyagi Prefecture, Japan \\ ${ }^{3}$ Matsunaga ltd., 5-18-19 Minamioizumi Nerimaku Tokyo, Japan
}

\begin{abstract}
In order to retain good indoor air quality through the year in detached houses with passive ventilation systems, the authors investigated a mechanical control air-supply method. Firstly, indoor environments in houses with passive ventilation systems with thermal dampers, were examined using a simulation program (Fresh). Secondly, a passive ventilation system with a thermal damper, an under-floorheating system with a heat pump and were installed in an airtight house at Maebashi in Japan and measurements on its ventilation characteristics and indoor air quality were made. The simulation results showed that if the thermal damper is well tuned, this mechanically controlled air-supply opening keeps ventilation rates adequate through the year especially in airtight houses. The measurement results showed that the ventilation rates were kept above the required level through the year and the TVOC concentration decreases from 3000 to $200 \mu \mathrm{g} / \mathrm{m}^{3}$ in 5 months after the construction.
\end{abstract}

\section{Introduction}

Passive ventilation systems (PVS) have been used in detached houses in Hokkaido, the coldest area of Japan, since 1990s. The benefits of PVS are that it does not need electrical energy for fans and that its maintenance work is easy for the dwellers. The most beneficial point of PVS is that it keeps ventilation rates adequate without operation by dwellers, so it is a fail-safe system in retaining good indoor air quality in houses. However, ventilation rates depend on weather conditions. Ventilation with PVS is not enough in warm seasons. The lack of ventilation is a problem in most areas of Japan, so a hybrid ventilation system (HVS) was developed using an airflow sensor and a mechanical fan in 1999 and it is now widely used in Japan. On the other hand, PVS is beginning to be used in warm area of Japan as a ventilation system for winter. In order to keep ventilation rates adequate in both winter and mild seasons, a passive ventilation system using mechanical thermal dampers TD controlled by supply air temperature was designed.

\section{Methods}

The system consists of a stack and an air supply route with a damper. The equivalent leakage area of TD changes with the temperature of supply air. This change of the equivalent leakage area has to be adjusted considering weather conditions and required ventilation rates. In order to develop an optimum method of retaining indoor air quality and at the same time saving energy, the following studies were carried out.

\subsection{Optimization of thermal damper}

An airflow ratio at an air supply opening: $a_{1}$ is calculated from the airflow ratio of an exhaust opening: $a_{2}$ and the required airflow rate: $Q_{\text {req }}$ as follows. The outdoor air pressure at the height of the air supply opening: $P_{o}$ is used as standard pressure. When the index of airflow characteristics : $\mathrm{n}_{1}(1.0-2.0)$ is the same as $\mathrm{n}_{2}\left(\mathrm{n}_{1}=\mathrm{n}_{2}=\mathrm{n}\right)$, the following equations are obtained.

$$
\begin{aligned}
\mathrm{Q}_{\text {req }} & =\mathrm{a}_{1} \Delta \mathrm{p}_{1}{ }^{1 / \mathrm{n}} \\
-\mathrm{Q}_{\text {req }} & =-\mathrm{a}_{2}\left(-\Delta \mathrm{p}_{2}\right)^{1 / \mathrm{n}} \\
\Delta \mathrm{p}_{1} & =-\mathrm{P}_{\mathrm{i}} \\
\Delta \mathrm{p}_{2} & =\left(-\mathrm{h} \rho_{\mathrm{o}}\right)-\left(\mathrm{P}_{\mathrm{i}}-\mathrm{h} \rho_{\mathrm{i}}\right)=-\mathrm{P}_{\mathrm{i}}-\mathrm{h}\left(\rho_{\mathrm{o}}-\rho_{\mathrm{i}}\right)
\end{aligned}
$$

Where, $\rho_{\mathrm{o}}$ : density of outdoor air $=353 /\left(273+\theta_{\mathrm{o}}\right)\left(\mathrm{kg} / \mathrm{m}^{3}\right)$, $\rho_{\mathrm{i}}$ : density of indoor air $=353 /\left(273+\theta_{\mathrm{i}}\right), \theta_{\mathrm{o}}$ : outdoor temperature(deg-C), $\theta_{\mathrm{i}}$ : indoor air temperature, $\Delta \mathrm{p}_{1}$ : pressure difference at supply opening(mmAq), $\Delta \mathrm{p}_{2}$ : pressure difference at stack, $\mathrm{P}_{\mathrm{i}}$ : indoor pressure at the supply opening, $\mathrm{h}$ :hight of $\operatorname{stack}(\mathrm{m})$.

The next equation is obtained from (3) and (1).

$$
\mathrm{Q}_{\text {req }}=\mathrm{a}_{1}\left(-\mathrm{P}_{\mathrm{i}}\right)^{1 / \mathrm{n}}
$$

The next equation is obtained from (4) and (2).

\footnotetext{
* Corresponding author: author@e-mail.org
} 


$$
-Q_{\text {req }}=-a_{2}\left(P_{i}+h\left(\rho_{0}-\rho_{i}\right)\right)^{1 / n}
$$

The next equation is obtained from (5) and (6).

$$
\begin{aligned}
& Q_{\text {req }}=a_{1}\left(-P_{i}\right)^{1 / n}=a_{2}\left(P_{i}+h\left(\rho_{0}-\rho_{i}\right)\right)^{1 / n} \\
& \delta a_{2}\left(-P_{i}\right)^{1 / n}=a_{2}\left(P_{i}+h\left(\rho_{o}-\rho_{i}\right)\right)^{1 / n}
\end{aligned}
$$

Where, $\delta=\mathrm{a}_{1} / \mathrm{a}_{2}$

$$
\mathrm{P}_{\mathrm{i}}=-\mathrm{h}\left(\rho_{\mathrm{o}}-\rho_{\mathrm{i}}\right) /\left(1+\delta^{\mathrm{n}}\right)
$$

The next equation is obtained from (9) and (5).

$$
\begin{aligned}
\mathrm{Q}_{\text {req }} & =\mathrm{a}_{1}\left(\mathrm{~h}\left(\rho_{\mathrm{o}}-\rho_{\mathrm{i}}\right) /\left(1+\delta^{\mathrm{n}}\right)\right)^{1 / \mathrm{n}} \\
\mathrm{Q}_{\text {req }} & =\delta \mathrm{a}_{2}\left(\mathrm{~h}\left(\rho_{\mathrm{o}}-\rho_{\mathrm{i}}\right) /\left(1+\delta^{\mathrm{n}}\right)\right)^{1 / \mathrm{n}} \\
\delta & =-\mathrm{Q}_{\mathrm{req}} /\left(\mathrm{Q}_{\mathrm{req}}-\mathrm{a}_{2} \mathrm{~h}\left(\rho_{\mathrm{o}}-\rho_{\mathrm{i}}\right)\right)^{-1 / \mathrm{n}}
\end{aligned}
$$

Fig.2 shows relationships between outdoor temperature and $\delta$. The ratio $\delta$ is lower in the case where $\mathrm{n}=2.0$.

\subsection{Simulation of ventilation}

Airflow networks were calculated using leakage network models of airtight wooden houses (2 inch x 4 inch) stud structure. The equivalent leakage area is $0.5 \mathrm{~cm}^{2} / \mathrm{m}^{2}$. The ventilation systems of simulation models were A_P (a passive ventilation system) and A_TP (a passive ventilation system with $\mathrm{TD}$ ). The equivalent opening area of a stack is $313 \mathrm{~cm}^{2}$ in the case of A_P. That in the case of A_TP is $894 \mathrm{~cm}^{2}$. The height of stack is $8 \mathrm{~m}$. In the case of A_TP, in order to keep ventilation rate sufficient in mild seasons, the erea of stack have to be larger than that in passive ventilation A_P. The required air supply rate $\left(\mathrm{Q}_{\mathrm{req}}\right)$ is set to $120\left(\mathrm{~m}^{3} / \mathrm{h}\right)$.

"Fresh" simulates the temperatures, the airflow rates using the NHK standard living schedule model and the HASP weather data on Tokyo.Fig. 3 and 4 show the relationship between outdoor temperature and airflow rates. Of course, the airflow rates do not depend on outdoor temperature in the case of mechanical ventilation systems. However, in the case of A_P (Fig.3), the airflow rates depend on outdoor temperature. In the case of A_TP (Fig.4), the airflow rates do not depend on outdoor temperature.

The air supply rates and exhaust rates were widely distributed when outdoor temperature is high in both A_P and A_TP. When outdoor temperature is high and the temperature difference between inside and outside is small, the pressure difference is small. Therefore wind pressure influences the ventilation rates significantly. In the case of A_TD, the area of air supply routes is larger than that in A_P. Therefore, the distribution of ventilation rates is more significant, especially when outdoor temperature is high. These simulation results showed that TD is effective in keeping ventilation rates in mild seasons, but ventilation rates are strongly affected by wind pressure in mild seasons.

\subsection{Measurements on ventilation and I.A.Q.}

A thermal damper was designed and installed into an airtight house (floor area $: 94.5 \mathrm{~m}^{2}$ ) in Maebashi, Japan. Table 1 shows the outline of the house.The wooden beam and pillar is a common strcture and the insulation level is higher than the gereral level.The interior is made of general materials. The equivalent leakage area per floor area is $0.7\left(\mathrm{~cm}^{2} / \mathrm{m}^{2}, \mathrm{n}=1.6\right)$. The ventilation system and the heating system are different from gereral systems in Japan. In the house, an under-floor heating system is used. An air conditioning unit with a heat pump is
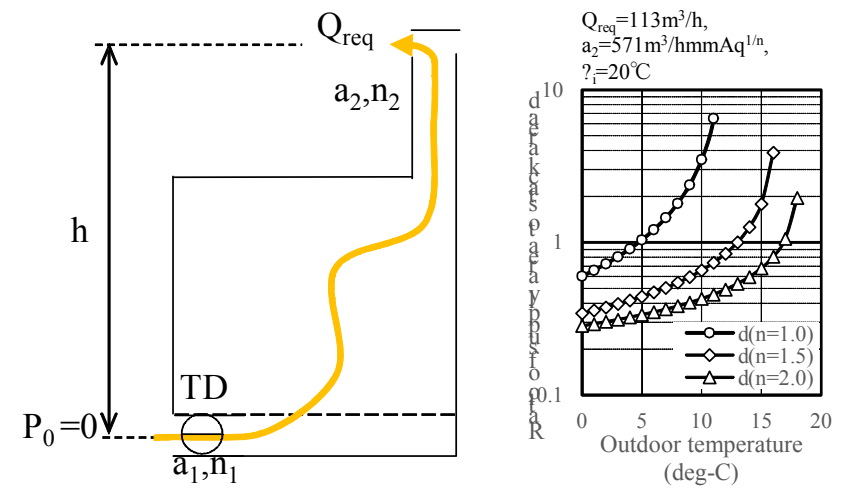

Fig. 1. Passive ventilation system Fig. 2. Outdoor temperature with thermal damper and Ratio $\delta$

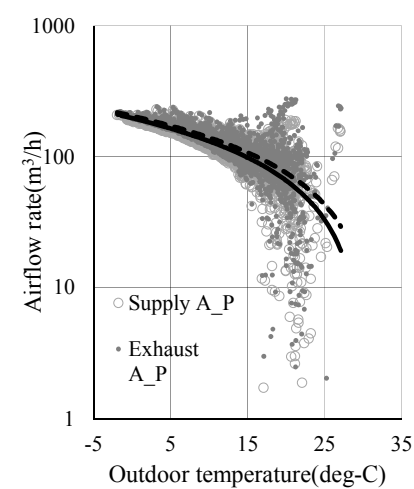

Fig. 3. Temperature and airflow rates in A_P

\begin{tabular}{|c|c|}
\hline Structure & Wooden beam and pillar \\
\hline Insulation & energy saving standard \\
\hline \multirow{3}{*}{ LDK } & floor: plywood(t24)+wooden floor(t18) +vegetable oi \\
\hline & wall: plasterboard(t12.5)+plaster \\
\hline & ceiling: plasterboard $(\mathrm{t} 9.5)+$ cloth \\
\hline \multirow{3}{*}{ Main bed room } & floor: plywood(t28)+plywood(t9)+cork \\
\hline & wall: plasterboard(t12.5)+plaster \\
\hline & ceiling: plasterboard $(\mathrm{t} 9.5)+$ cloth \\
\hline \multirow{3}{*}{ Japanese room } & floor: plywood(t9)+tatami mat(60) \\
\hline & wall: plasterboard(t12.5)+plaster \\
\hline & ceiling: wood(cedar) \\
\hline
\end{tabular}

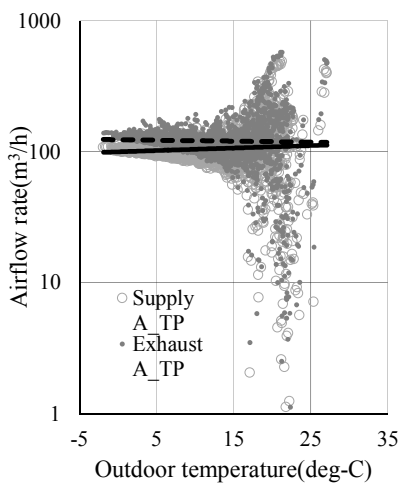

Fig. 4. Temperature and airflow rates in A_TD

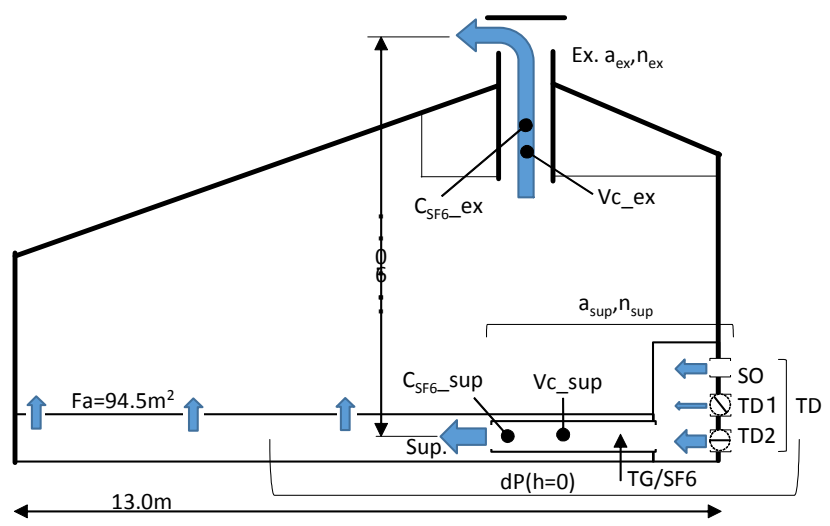

Fig. 5. Passive ventilation system with TD

Table 1 Outline of the house in Maebashi 
installed under the floor of utility spsce. Indoor air is heated and supplied to under floor space and the warmed air goes to indoor space through the openings on the floor. The ventilation system consists of a stack and an air supply opening. The equivalent leakage area of a stack is large : $400\left(\mathrm{~cm}^{2}, \mathrm{n}=2\right)$. The air supply opening consists of three openings as shown in Fig.5. SO is a simple opening. TD1 and TD2 are openings with thermal dampers. The opening areas change with temperatures as
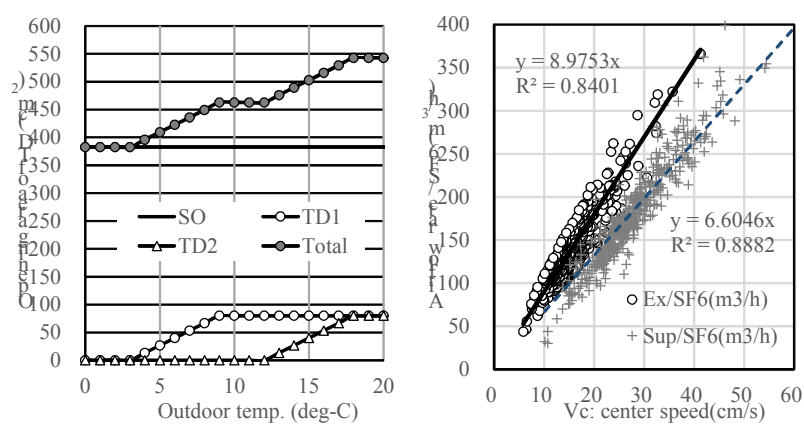

Fig. 6. Characteristics of TD Fig. 7. Ve and Af/SF6
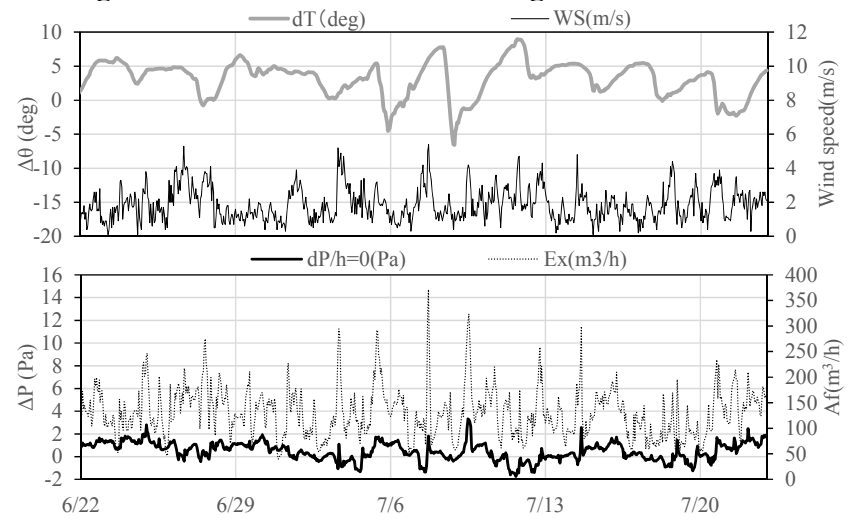

Fig. 8. Temp., wind and Airflow in summer

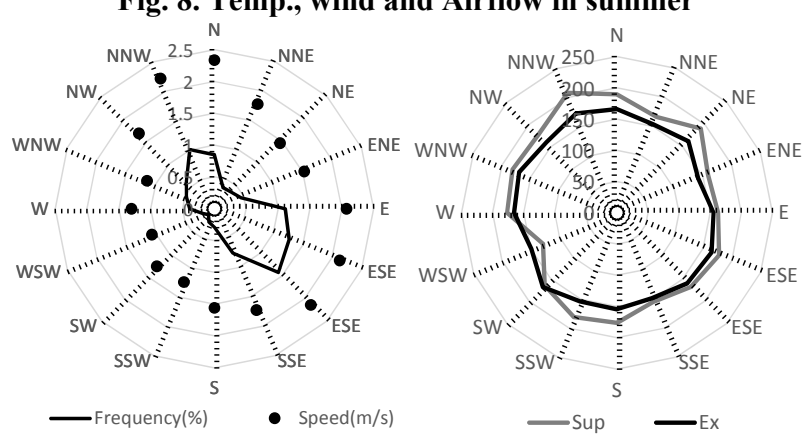

Fig. 9. Wind velocities and airflow rates

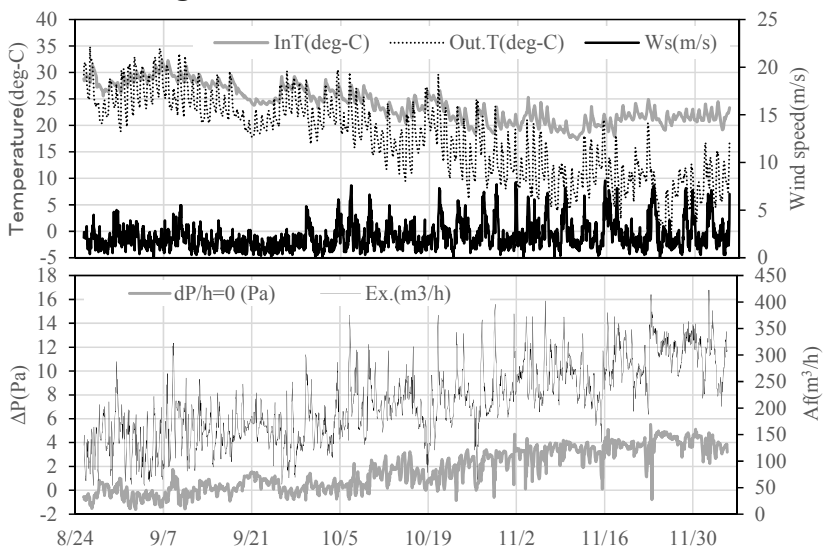

Fig. 10. Temperatures, wind velocities and airflow rates shown in Fig.6. Therefore, the air supply opening area changes when outdoor temperature is from 3 to $18 \mathrm{deg}-\mathrm{C}$. The change of air supply opening area is not the same as that of the above optimization results. However the ventilation rate is expected to be kept better in mild seasons.

The ventilation rates and the indoor air quality were measured from summer to winter. The air flow speeds are measuured using airflow sensors at the center of the stack and the air supply route. The air flow rates are calculated from these center speeds using the results of tracer gas (SF6 constant generation) methods as shown in Fig.7. And concentrations of VOCs (45 compounds) and Aldehydes are measured for one year and harf after the construction of this house. VOCs were sampled from the indoor air $(5 \mathrm{~L})$ using Tenax-TA in Grestel Tube. Aldehydes were sampled from the indoor air (30L) using DNPH. And the concentrations were analyzed using GCMS and HPLC of National Instutute of Public Health.

\section{Results and discussion}

Firstly, the influence of the wind is analysed using the results of the measurements in summer. Secondly, the influence of outdoor temperature is analysed using the measurement results from summer to winter. Lastly, the indoor air quality is analysed using the change of indoor chemical compounds concentrations.

\subsection{Influence of wind upon ventilation}

Fig. 8 shows the change of temperature differences, wind speed, pressure differences and airflow rates at the stack in summer. The temperature difference did not change significantly (-6 to $9 \mathrm{~Pa}$ ). However the airflow rates change significantly. Therefore, the ventilation rates are thought to depend basically upon the wind pressure fluctuation.

Fig.9 shows the wind velocity at the weather observation point of Maebashi and the airflow rates of the supply routes and the stack. The air supply opening is set on the east wall. Therefore the airflow rate is thought to increase when the wind direction is east. But, this figure shows that the airflow rates do not depend upon the wind direction.

\subsection{Influence of temperature upon ventilation}

Fig.10 shows the results of the measurements from August to December. Indoor temperature declined with the outdoor tepmerature in this term. And the temperature difference increased gradually. Wind speed also increased gradually. Both the pressure difference $\Delta p$ and the airflow rate at the stack Ex. increased with significant fluctuation.

Fig.11 shows the relationship between outdoor temperature and indoor tenperature and the relationship between outdoor temperature and temperature difference. And also the rerationship between the outdoor temperature and pressure difference is shown in this figure. These relasionships are simple and pressure difference depends on outdoor temperature. Indoor 
temperature increases with outdoor temperature. This shows that the ventilation power of temperature difference does not disappear also in mild seasons.

Fig.12 shows the airflow rates at the air supply route and the stack. Both airflow rates decrease when outdoor temperature is high. The tendency is more significant at the stack. This is because the flow is not controlled at the stack and the air flow at the air supply route is controlled by thermal dampers. Air exhaust rates at the stack are higher than air supply rates. The air infiltration through air leakages of a building and a solar air supply system is thought to cause the difference between echaust rates and supply rates. In the case of air supply rates, there is a significant gap at $3 \mathrm{deg}-\mathrm{C}$. This gap is thought to be caused by the discontinuous reaction of the thermal damper.

\subsection{Indoor air quality (I.A.Q)}

Fig.13 shows the concentrations of VOC and Fig.14 shows the concentrations of Aldehydes. Only the
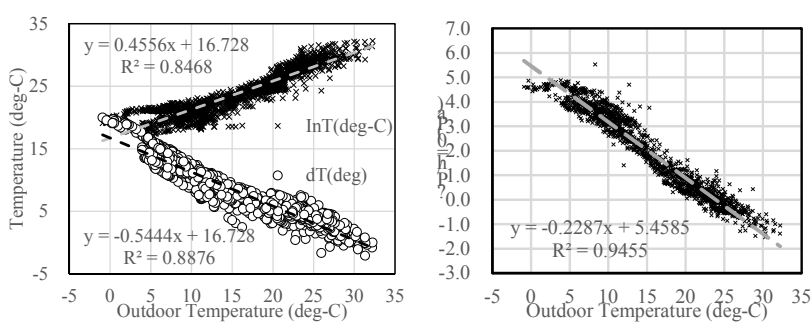

Fig. 11. Characteristics of temperature, wind and pressure
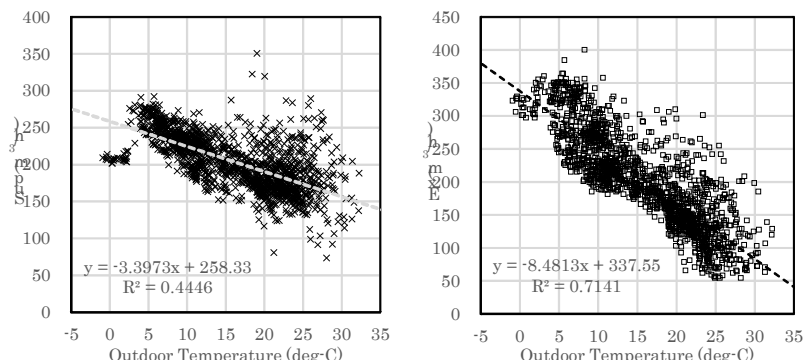

Fig. 12. Outdoor temperatures and airflow rates

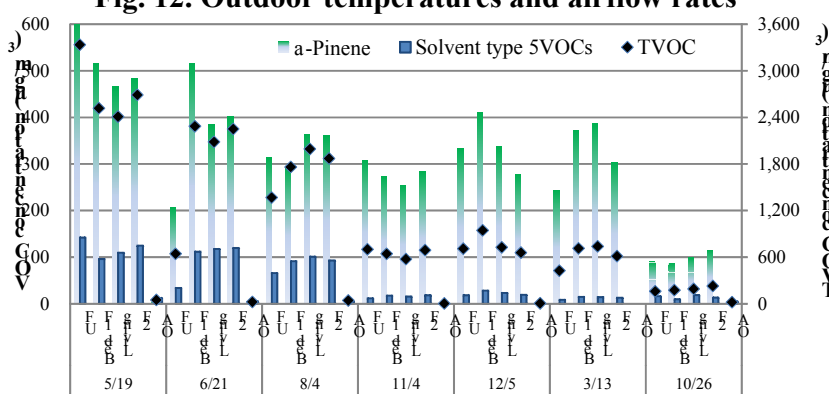

Fig. 13. Concentrations of VOCs and TVOC

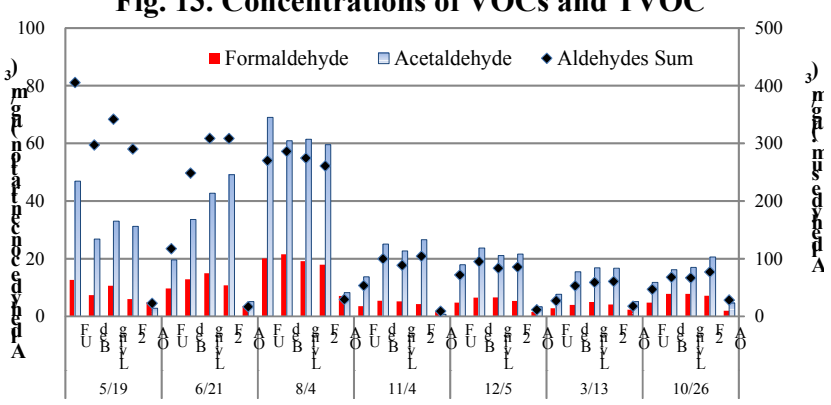

Fig. 14. Concentrations of aldehyde and the sum concentration of acetaldehyde was over the guideline of Ministry of Lobour and Wellfare (13 compounds and TVOC). The concentrations of most solvents (for example Toluen and Xylen) were low, but those of Methyl Isobutyl Ketone and Tetradecan were slightly higher for the first few months. These concentrations of solvent-type-VOC declined rapidly. The concentrations of conpounds which are thought to generate from wooden materials, were not low $\left(\alpha-P i n e n e: 520 \mu \mathrm{g} / \mathrm{m}^{3}, \mathrm{~d}-\right.$ Limonene: $\left.96 \mu \mathrm{g} / \mathrm{m}^{3}\right)$. TVOC was high at first $(2300$ $3300 \mu \mathrm{g} / \mathrm{m}^{3}$ ). This value was over the guide line (the provisional target value of TVOC $: 400 \mu \mathrm{g} / \mathrm{m}^{3}$ ). After 7 months, TVOC decrease to about $600 \mu \mathrm{g} / \mathrm{m}^{3}$. The decease of Solvent-type-VOC is thought to cause this decline of TVOC.Formaldehyde was $9 \mu \mathrm{g} / \mathrm{m}^{3}$ for the first month (May). And the concentration was not over the guid line $\left(100 \mu \mathrm{g} / \mathrm{m}^{3}\right)$ even in summer. Acetardehyde was $63 \mu \mathrm{g} / \mathrm{m}^{3}$ in summer and was over the guideline (48 $\left.\mu \mathrm{g} / \mathrm{m}^{3}\right)$. Methacroline was $65 \mu \mathrm{g} / \mathrm{m}^{3}$ a first and declined rapidly. Formaldehyde and Acetoaldehyde declined in the first summer, but did not decrease significantly after the first summer. These compounds were thought to generate in summer for a long time. It is necessary to keep ventilation rates sufficient in summer for better indoor air quality through the year.

\section{Acknowledgements}

The study was carried out by Grant-in-Aid Scientific Research of Japan Society for the Promotion of Science. The study was carried out with the cooperation of $\mathrm{Mr}$. Misao Kumaido and the members of Passive Technology Study Group.

\section{References}

1. N.Aratani,N.Sasaki,M.Enai,A Successive Integration Method for the Analysis of the Thermal Environment of Building, Building Science Series 39 of NBS, 305-316, 1971

2. C.Y.Shaw and A.Kim, "Performance of passive ventilation system in a two-story house" DBR Paper No.1276 1984 October 1-4 p.11.1-11.27

3. M.Hayashi,M.Enai,Y.Hirokawa, Annual Characteristics of Ventilation and Indoor Air Quality in Detached Houses using a Simulation Method with Japanese Daily Schedule Model, The International Journal of Building Science and its Applications BUILDING AND ENVIRONMENT Vol.36, pp.721-731,2001

4. M.Hayashi, H.Osawa, Y.Honma and M.Matsui, Prediction of air quality considering the concealed air leaks of houses, Proc.int.conf. "Building Simulation 2007”,870-877.

5. M.Hayashi and H.Osawa, The influence of the concealed pollution sources upon the indoor air quality in houses, Building and Environment, Vol.43, Issue 3, March 2008, 329-336.

6. Motoya Hayashi. Annual Characteristics of a Passive Stack Ventilation System with Mechanically Controlled Air Supply Openings, Building Simulation 2017. Proceedings 2017.8; Sanfransisco, USA, 5 pages (Electronic file) 